\title{
UNIVERSITYOF
}

FORWARD

THINKING

WESTMINSTER用

WestminsterResearch

http://www.westminster.ac.uk/westminsterresearch

\section{Assessing the Exchange of Knowledge Between Operations \\ Management and other Fields: Some Challenges and \\ Opportunities}

Pilkington, A. and Meredith, J.

NOTICE: this is the authors' version of a work that was accepted for publication in Journal of Operations Management. Changes resulting from the publishing process, such as peer review, editing, corrections, structural formatting, and other quality control mechanisms may not be reflected in this document. Changes may have been made to this work since it was submitted for publication. A definitive version was subsequently published in the Journal of Operations Management, 60, pp. 47-53, 2018.

The final definitive version in Journal of Operations Management is available online at: https://dx.doi.org/10.1016/j.jom.2018.05.004

(c) 2018. This manuscript version is made available under the CC-BY-NC-ND 4.0 license https://creativecommons.org/licenses/by-nc-nd/4.0/

The WestminsterResearch online digital archive at the University of Westminster aims to make the research output of the University available to a wider audience. Copyright and Moral Rights remain with the authors and/or copyright owners.

Whilst further distribution of specific materials from within this archive is forbidden, you may freely distribute the URL of WestminsterResearch: ((http://westminsterresearch.wmin.ac.uk/).

In case of abuse or copyright appearing without permission e-mail repository@westminster.ac.uk 


\title{
Assessing the Exchange of Knowledge Between Operations Management and other Fields: Some Challenges and Opportunities
}

\author{
Jack R. Meredith* \\ Wake Forest University \\ PO Box7897 \\ Winston-Salem, NC 27109 \\ Email: meredij@@wfu.edu \\ Alan Pilkington \\ Westminster Business School \\ University of Westminster \\ United Kingdom \\ Email: A.Pilkington@Westminster.ac.uk
}

May 20, 2018

${ }^{*}$ Corresponding author

\begin{abstract}
Addressing a suspicion that the field of Operations Management (OM) draws substantially more knowledge from non-OM journals than those journals draw from OM journals in return, we studied the citations of the top 30 research journals of interest to our field. We conducted citation analyses of the three oldest OM journals over three decades in comparison to the 27 other journals representing the fields of Management, Operations Research/Management Science (OR/MS), Marketing, Practice, and Engineering. We examined both the entire 30-year period and then each decade separately. Our suspicions were confirmed-although citations from these 27 journals to these three OM journals have increased by a factor of 7 over the three decades, we in OM still cite these journals about twenty-five times more often than they cite our journals, giving an indication of the knowledge development and flows among these fields. We then describe some challenges for the field of OM in providing more research knowledge to other fields but also some opportunities that OM should be able to capitalize on, such as our historic ties to practice and our escalating research in strategic and organizational issues.
\end{abstract}

Keywords: research, knowledge exchange, citations, networks, source journals 


\section{Introduction}

The field of Operations Management (OM) has substantially developed its research strength over the last four decades: At least five research journals include "operations management" in their title, and three of those are included in the FT50 list of premier journals. Other OM journals include some specific element of the field in their title such as supply chain, production, logistics, manufacturing, quality, distribution, scheduling, purchasing, materials, inventory, and so on. Although the OM field's history dates back to Fred Taylor's "factory management" in the late 1800s, the founding of peer-reviewed academic journals in OM only began in 1980.

More than a quarter century later, the OM field now can be considered as "mature," according to the guidelines suggested by Nerur et al. (2016, p. 1068) in presenting their citation study of the Strategic Management Journal covering a similar period of time: "As an academic field reaches maturity, it is common for scholars to undertake detailed analyses of the field itself in order to delineate its domain, explain its evolutionary patterns, identify significant intellectual influences, assess its contributions, and plan its future." Here we hope to analyze the flows of knowledge between $\mathrm{OM}$ and its sister fields in both academia and practice, since it informs our reflection on how the field has been developing.

The OM field has historically been strongly focused on practice, which in early years yielded research that aimed to solve practical problems. Recently, however, we have joined our sister business disciplines in seeking to develop generalizable theories by borrowing theory from other disciplines-management, management science/operations research, marketing, engineering, practice-and using it for developing insights and knowledge specific to OM. As Abbott (2001) suggested, the process by which disciplines become established is a social one where groups stake claims for tools, solutions, and concerns as "experts."

We begin by exploring how the knowledge transfer process between OM and its sister fields has evolved over recent decades. Specifically, we identify which fields, as represented by their journals, OM has borrowed knowledge from over the last three decades and given knowledge back to. As we observe these flows of knowledge, it informs our reflection on how the field has been developing. This then gives insight into the threats and opportunities that lie before us.

In contrast to Linderman's and Chandrasekaran's (2010) analysis of the exchange of knowledge during the period 1998-2007 between OM journals and our sister fields of management, marketing, and finance, we examine all the references made in three base $\mathrm{OM}$ journals from the beginning of peer-reviewed research in the field in 1980 and identify the major journals referenced regardless of their field. We capture the relative citation flows between the OM journals as a group and the other fields to which the OM journals are connected via citations, and how these flows have evolved over the three decades of the 1980s, the 1990s, and the 2000s. Based on these flows and their evolution, we draw conclusions about the challenges and opportunities that peer-reviewed research in the OM field is facing. We conclude by sharing thoughts about the way forward. 


\section{Literature review}

As Linderman and Chandrasekaran (2010, p. 357-8) noted, cutting-edge science increasingly involves collaboration across disciplinary boundaries (Rinia et al., 2002). Since a narrow disciplinary focus can hinder the development of a field, it is very positive that scholars in the OM field are actively exchanging ideas with other disciplines to enhance learning and create knowledge. For most fields, journals provide the main mechanism for distributing and archiving scholarly research and ideas (Cole and Cole, 1973), and thus provide a longitudinal lens for discerning the evolution and trends of a discipline (Barman et al., 1991; Baumgartner and Pieters, 2003; Franke et al., 1990).

As Agarwal and Hoetker (2007, p. 1305) noted: "Researchers have found that the knowledge imported from related industries helps a new industry to leverage established distribution networks, develop new knowledge, and increase in legitimacy, all of which enable it to take off and grow." Amundson (1998, p. 347) agreed: "OM borrows from other fields for understanding the nature and purpose of theory. In addition, OM may examine theories from other fields while working on interdisciplinary research problems, or OM may study theories from other fields for ideas and insights for OM theory building." However, Agarwal and Hoetker (2007, p. 1306) also noted that "... the relative importance of knowledge from outside an industry's boundaries decreases as the industry matures."

This paper conducts its investigation using the bibliometric method of citation analysis, a widely used approach in many fields such as inventions (e.g., Lee et al., 2010) and innovations (Fox et al., 2013), engineering technology (Pilkington, 2008), and extensively in business. Some examples in business include strategy (Nerur et al., 2016; Ramos-Rodriguez and Ruiz-Navarro, 2004; Franke et al., 1990), marketing (Baumgartner and Pieters, 2003; Stremersch et al., 2007; Zinkhen et al., 1992), information systems (Holsapple et al., 1993, 1994; Wade et al., 2006), and OM. In OM, citation analysis has been used most recently to identify the leading European OM researchers (Behara and Babbar, 2014), to investigate supply chains (Kim et al., 2011), to determine scholarly exchanges of knowledge (Linderman and Chandrasekaran, 2010), to analyze the major articles and subfields within OM (Pilkington and Meredith, 2009; Pilkington and Fitzgerald, 2006), to evaluate the differences in the research agenda between OM scholars in Europe and America (Pilkington and Liston-Hayes, 1999), and to rank the top journals in the field (Goh et al., 1997; Vokurka, 1996).

\section{Data and methodology}

The analysis presented builds on a database of references in the oldest journals totally dedicated to the field of OM, which we refer to as our "base" journals: Journal of Operations Management (JOM, initiated in 1980), International Journal of Operations and Production Management (IJOPM, also initiated in 1980), and Production and Operations Management (POM, initiated in 1992), extending through the decades of the 1980s, the 1990s, and the 2000s. We assumed that all the articles in these three journals were purely OM articles, thereby avoiding having to decide whether articles from multi-discipline journals like Management Science and Decision Sciences were OM articles or not. We also wanted to be sure to include all forms of OM articles, so we selected JOM for its empirical articles, POM for its 
more quantitative articles, and IJOPM for its international and practice-oriented articles. As long as we covered all forms of OM articles, and only OM articles, we felt it was unnecessary to include other journals in the base to reveal the flows of knowledge over the three decades.

We primarily relied upon the ISI's Social Science Citation Index (SSCI) for our data but supplemented with other sources when particular issues of our base journals were not listed. Since we were only interested in research journals, we excluded books and any other nonjournal references. We employed MATLAB (MATLAB, 2012), Bibexcel (Persson et al., 2009), UCINET/NetDraw (Borgatti, 2002; Borgatti et al., 2012), and Excel for text manipulation, data preparation/manipulation, and visualization of the networks.

As noted earlier, we use citation analysis of the set of journals identified as most important to the field of OM over the three decades 1980-2009 to conduct our study. As Nerur et al. $(2016$, p. 1066$)$ stated: “...a study of citation relationships across journals can provide valuable insights about the intellectual evolution and knowledge structure of a field as well as the pattern of idea migration across disciplines." Nerur et al. went on to explain that a citation analysis "...can provide an assessment of the contribution of the field ... to other intellectual niches within the field ... and beyond, thus demonstrating its legitimacy or lack thereof as a vibrant discipline." And, it "... can establish the centrality or peripherality of specific journals within a network."

\section{Analysis and results}

\subsection{The top-30 journals}

Table 1 lists the 30 top journals of major importance to operations management between 1980 and 2009 (Pilkington and Meredith, 2017) based on the number of citations in the three base OM journals. The youngest journal in the list is POM, having started publication in 1992. The journals are listed in order of their percentage of the 298,217 citations by the 30 journals to the other 29 (no self-citations), followed by their abbreviations. The values in the \% Cites column exclude self-citations, with MS garnering over 15 percent of all citations in the group followed in order by ASQ, OR, and AMJ. It should be noted that some of the journals are very broad and appeal to all areas of business (e.g., MS, DS, and most of the Practice journals like HBR) so they will naturally tend to have more citations than journals from narrowlyoriented journals like IEEETEM.

In the last column are our designations for each journal in terms of its knowledge flows between the journals. There are three categories based on Biehl (2006): whether a journal is considered a "source" of knowledge that other journals depend upon, a "sink" that mostly depends on other journals' knowledge, or something between the two, called a "transmitter." The ratio of the number of citations to a journal (excluding self-citations) divided by the number of citations made by the journal allowed us to differentiate between the categories, with a ratio greater than 1.5 indicating that this journal is a source and, for symmetry, less than 0.5 indicating a sink, with all in-between ratios indicating the journals as transmitters.

TABLE 1 HERE 


\subsection{Grouping the journals}

Our focus in this analysis is on the journals OM relies upon for research knowledge and the fields those journals represent, and the fields that in turn utilize the knowledge in our OM journals. That is, our interest is on the interchange of knowledge between the fields (represented by those journals) most important to OM, not the individual journals themselves. To better see the citation flows between $\mathrm{OM}$ and its sister disciplines, we have grouped the journals into the following five fields based on Harzing (2017) and ABS (2015): Management, Operations Research/Management Science, Practice, Engineering, and Marketing. Engineering and Practice were included because OM's beginnings were very technical and practiceoriented.

In many cases, it was difficult to put a journal into a group. For OM, we only considered a journal part of the OM group if more than 10 percent of its references were to the three base OM journals; that left only the three base OM journals representing the OM group. We also decided that it did not make sense to establish a one-journal group (e.g., psychology, economics) if it fit into one of the other groups also. Our last dilemma was what to do with journals that were clearly practice-oriented but also clearly (non-academic) management such as Business Horizons, California Management Review, Harvard Business Review, and Sloan Management Review, so we put them in a "practice" group.

Our final grouping of journals was as follows:

- Management: represented by Academy of Management Journal, Academy of Management Review, Administrative Science Quarterly, Journal of Management, Journal of Management Studies, Long Range Planning, Organization Science, and Strategic Management Journal.

- Operations Research/Management Science: represented by Decision Sciences, European Journal of Operational Research, Interfaces, International Journal of Production Economics, International Journal of Production Research, Management Science, Naval Research Logistics, Omega, and Operations Research.

- Practice: represented by Business Horizons, California Management Review, Harvard Business Review, Psychological Bulletin, and Sloan Management Review.

- Operations Management: represented by International Journal of Operations and Production Management, Journal of Operations Management, and Production and Operations Management.

- Engineering: represented by IEEE Transactions on Engineering Management, IIE (now IISE) Transactions, and Industrial Engineering.

- Marketing: represented by Journal of Marketing and Journal of Marketing Research.

Figure 1 illustrates the knowledge flows between each of the journals over the 30-year period using a Design Structure Matrix (Browning, 2016; Eppinger and Browning, 2012;

Steward, 1981) format. The journals are organized by the groups above, with the referencing journals on the left, identified by their abbreviations in Table 1, and the cited journals on the top. Each cell shows the number of citations (excluding self-citations of every journal) with a large black circle, small black circle, small empty circle, or nothing, from the referencing journal 
to the cited journal. A large black circle indicates over 1500 citations, a small black circle between 701-1500 citations, a small empty circle between 245-700 citations, and no symbol less than 245 citations. Source journals are shown on the diagonal with a small or large triangle, transmitter journals with a small or large square, and sink journals with a small inverted triangle. The source and transmitter symbols have two sizes here to show substantial differences in the magnitude of their citations, with the MS/OR group having all three of the larger symbols. The journal MS was found to be the major source among all the journals, and EJOR and IJPR were the major transmitters.

\section{FIGURE 1 HERE}

Examining Figure 1, we see that the Management group in the upper-left has 4 source journals, 2 transmitters, and 2 sinks. In addition to extensive cross referencing of each of the other journals in the Management group, they also tend to reference MS and the Practice group of journals. Next on the diagonal is the MS/OR group with 2 source journals (MS being the largest in the network), 3 transmitters, and 4 sinks. Like the Management group, they also tend to cross reference each other heavily, plus HBR, SMJ, IIET, and JOM, as well as all the other groups generally. Next on the diagonal are the Practice journals with 1 source journal (HBR), 3 transmitters, and 1 sink. In contrast to the other groups, this group generally does not reference any of the other journals, except for minimal references to HBRand ASQ. The three OM journals come next with 1 transmitter and 2 sinks, and since this group generated the list of the other 27 journals, it would be expected to relatively evenly reference all the areas. Next, the Engineering journals with 1 transmitter and 2 sinks do not seem to significantly reference the other groups except for MS and OR. And finally, the Marketing journals with 2 transmitters reference each other heavily but not much else.

There were two exceptions to our diagramming process here due to a lack of referencing information: 1 ) we designated HBR as a source due to its many citations, but it stopped making references after 1991, and 2) we did not have any information about IE's references, so we labeled it as a sink based on its low citations.

\subsection{Analyzing the knowledge flows between groups}

Table 2 presents the aggregate statistics for the six groups above in terms of the percentage of their citations to the three base OM journals and the percentage of the three OM journals' citations to any journal in that group, all listed for the 30-year period overall and then for each of the decades of the $80 \mathrm{~s}$, the $90 \mathrm{~s}$, and the $00 \mathrm{~s}$. As seen in the Total row of the 30-year Overall column, OM received only a bit more than 4 percent of the 298,217 citations from these top-30 journals, but the trend shown by the decade columns shows a substantial growth from less than one percent (of 35,548 citations) in the 1980s to almost 6 percent (of 171,247 citations) in the 2000s. However, this may be partly due to the initiation of the POM journal in 1992, since most of that growth is from the top-citing OR/MS group, which increased its citations to OM about 6 times over the decades. Similarly, Engineering has tripled its citations to OM over the decades, though still accounting for less than one percent of the citations. The last three groups of Management, Practice, and Marketing have not changed substantially over the decades, 
despite our close identification with both Management and Practice, and many common interests with Marketing, such as Supply Chain Management. But even combined, their citations amount to only about a tenth of one percent.

\section{TABLE 2 HERE}

Considering now the citation percentages from OM to each of these groups, we see that despite OR/MS increasing its citations to OM over the three decades by a factor of six, OM has reduced its citations to OR/MS in half; however, OM still cites OR/MS ten times as often as the reverse. Similarly, we see that while Engineering has tripled its references to the OM group over the three decades, OM has reduced its references to Engineering by more than two-thirds to three percent, with most of the decrease being redirected to the Management group, plus some from the reduction in references to the OR/MS group. And again, OM is still referencing Engineering ten times as often as vice-versa. Next, we see that Management has basically maintained its percentages of references to $\mathrm{OM}, \mathrm{OM}$ has almost tripled its references to Management, reaching fully one-quarter of all its references. So too, Practice has largely maintained its trivial level of references to $O M$ while $O M$ has also maintained its substantial level of references to Practice. Finally, while Marketing barely references OM, OM has increased its references to Marketing by a factor of seven, to seven percent, again probably due to the topic of supply chain management.

The knowledge flows between all of these six groups over the three decades are depicted in Figures 2a (1980s), 2b (1990s), and 2c (2000s). The size of the nodes reflects the number of citations that a given group receives from the other groups and from other journals in its own group. The arrow links indicate the number of references from each group (arrow tail) to each of the other groups (arrowhead). Three thicknesses of arrows are shown to indicate the number of the references.

In Figure 2a for the 80s, we see the dominance of the OR/MS group, followed by a somewhat smaller Management group, and then the other groups, with OM being the smallest. The two major flows here are from Engineering to OR/MS and from Management to Practice. The seven secondary flows are between OR/MS and Management; from OR/MS to Engineering, Marketing, and Practice, from OM to OR/MS, and from Marketing to Practice. The locations of the nodes with respect to each other are also of significance, showing the central role of $\mathrm{OR} / \mathrm{MS}$, and secondarily Management, in the network. On the other hand, there is a great distance between $\mathrm{OM}$ and Marketing, as well as between Engineering and Practice.

\section{FIGURE 2a HERE}

Turning next to Figure $2 b$ for the 1990s, we see that Management has increased in size while Marketing, Engineering, and Practice have all slightly reduced in size. Also, the positions of Marketing and Engineering have reversed with Marketing now much closer to OM and Engineering further away from OM. But OM has also moved much closer to OR/MS, Practice, and Management. We also see considerable strengthening of the links, meaning increasing references, especially between OR/MS and the other groups. There are now 9 major flows between the groups and six secondary flows. 
Last is Figure 2c for the 2000s, where we see that Management is now just as large as $\mathrm{OR} / \mathrm{MS}$, and Engineering and Practice have reduced a bit further in size while OM has increased to the size of Marketing. And the referencing continues to increase, with 13 major flows and 6 secondary flows, indicating the increasing level of cross-referencing between the fields, especially from OM to Marketing, which may relate to the fact that OM research increasingly considers both the operation and the supply chain.

\section{FIGURE 2C HERE}

\section{Interpretation}

Considering first the changes in knowledge flows over the decades between these major groups of importance to $\mathrm{OM}$, we see some interesting modifications occurring. One obvious one is the increasing importance of Management among the groups and the somewhat decreasing importance of Practice-we discuss this topic further in the next section. Another is the clearly noticeable strengthening of ties between the groups over the decades, as indicated by the thickness of the links in Figures 2. And a third, more visible in Table 2 than Figure 2, is the movement of OM referencing away from Engineering and toward Marketing, as noted earlier, and even more substantially away from OR/MS and toward Management.

OM's position in terms of referencing other groups has increased noticeably over the decades as seen in Figures $2 \mathrm{a}$ and $2 \mathrm{c}$; where OM had only one medium arrow (to OR/MS) in the 1980s, in the 2000s it has four major outbound reference arrows to the other groups and one medium arrow to Engineering. However, in terms of inbound citation arrows, it has only one major arrow (from OR/MS), while Management has four, Practice and OR/MS have three, and Marketing has two.

We can thus conclude that $\mathrm{OM}$, starting with no peer-reviewed journals of its own four decades ago, has been creating valued research for the journals and groups (Table 2 Total row) of most importance to it-- that is, sharing its knowledge with its sister groups. Moreover, it would appear that there is much more that OM can offer through its research on topics of interest to these closely related fields. We next investigate the challenges facing OM in more detail, and then conclude with an elaboration of the opportunities available to the field.

\section{Some challenges}

OM has been late to the journal publications party, not even having its own journals until the 1980s, and then adding more since then such as POM in the 1990s and now Manufacturing and Service Operations Management (MSOM) in 1999 and Operations Management Research (OMR) in 2008. Prior to the 1980s, OM research was primarily published in engineering, OR/MS, and practice journals, and more recently in DS and IJPR.

\subsection{The OM and MS/OR split}

One reason OM was late with its own research journals was the explosion of management science and operations research and their journals on the scene in the 1960s, 
which OM put to great use solving myriad factory and service sector problems facing managers in those industries, and then extending their application into non-profit and governmental institutions (e.g., Meredith, 1973, 1976). The close relationship between OM and MS/OR gave OM another outlet for research publications in the new journals such as MS, OR, DS, EJOR, and others that had sprung up to showcase the great practical potential of these operations research and statistical tools.

Although other functional fields of business such as marketing and finance also benefitted from the MS/OR movement, none were as intimately identified with MS/OR as OM, which then came to be considered as simply applied management science. This led to an unfortunate split in the field which still haunts OM today and greatly hampers its future development. It is inconceivable to imagine marketing, for example, as dividing its societies between researchers who use operations research techniques and those who do not, or between those who use empirical data and those who do not. OM needs to pull its various factions together somehow if it is to move forward in providing research of value to its sister business disciplines. OM can provide valuable research knowledge to both academia and practice by identifying and helping solve the problems industry faces in getting the theories, tools, and models generated by our sister disciplines implemented successfully.

\subsection{Balancing strategic and tactical concerns}

Another challenge is the movement of practice away from tactical concerns and toward strategic, financial, global, and societal concerns. An example is the challenges posed by the mega-projects our industry and government agencies face with projects that involve dozens of organizations, a wide variety of stakeholders (such as regulators, the public, multiple agencies, and profit-making organizations), costs that run into the billions of dollars, social capital problems involving trust, communication, coordination, and so on. These projects involve multiple aspects of OM such as resources, project management, supply chains, quality, scheduling, efficiency, and most important, strategic effectiveness.

We see this movement not just in the managerial practice journals $B H, C M R, H B R$, and SMR but in the newspapers, magazines, and everywhere. Yet, OM has an important research role to play in the areas of strategy, profitability, sustainability, and the human aspects of work and production. We have made good progress in behavioral operations so far, but these strategic and organizational issues are now commanding our attention. OM needs to move its vision further up, into the higher reaches of its endeavors.

\subsection{Balancing academic rigor and practical relevance}

This last challenge is a tough one, the natural "academic drift" (Meredith, 2001) of research publications. OM has always been closely tied to practice, but the premier academic journals ( $A+$ journals such as those on the FT50 list) are considered by many to be more distant from practice than 40 years ago. A group called Responsible Research in Business and Management (www.rrbm.network) has even been recently formed to try to correct this situation.

Yet, the search for generalizability is complicated by the messiness involved in solving practical problems. This discouragement from tainting academic rigor with relevance is consistent with the shrinking size of the Practice node in Figures 2a-c, while the Management node is increasing. Thought leaders in the OM field need to create space for research that both creates knowledge that will change what practitioners do and can also be published in top journals. 
Our experience over the years is that this requires investment both among the top academic journals, as well as encouragement and respect for intermediate journals that create space for exploring interesting ideas-- OMR was created for exactly this reason. We need a less simplistic model of knowledge creation that includes what is learned in answering questions from practice. We also need more space for constructive disagreement. But publishing in other than top journals is risky before tenure. The scholars who should be filling these "space for pondering" journals should thus be senior academics who can afford to explore new territory. And, ideally, some top journals will come up with extended models of academic knowledge creation that will leave more space for rigor combined with relevance. If publishing pure theory in top journals means the only people reading our papers will be academics, we may be a dying breed!

One approach to the challenge of trying to choose between highly respected academic journals and intermediate journals that are of little help in gaining promotion is to consider some of the intermediate journals that appreciate theory, but mainly as a lens when applied for improving management practice. As Amundson (1998, p. 346) noted: “...does OM create and use 'lenses' which only fit the eyes of researchers, or should those lenses be capable of being utilized by both researchers and practicing managers?" And (p. 356): "The ability to satisfy both other researchers and practicing managers is 'easier said than done', but it is absolutely essential that OM researchers meet the needs of multiple constituencies for the future of the field."

\section{Opportunities for expanding OM's horizons}

The first of the new Forum pieces in JOM (Ketokivi, 2016) built on our inherent ability in OM to simultaneously relate to new developments in real-world practice such as supply chain management but also stay abreast of our sister academic disciplines. Our analysis above shows that whilst we are strong on using ideas from multiple other disciplines, we have had a limited impact, so far, on influencing other academic researchers. One opportunity for improving our influence is to illustrate how we link insights from other fields of management together through our interface with actual practice, and showing how the difficulties of implementing those theories and insights allow us to better inform these fields about the work that still needs to be done. In that way, our work can serve as a building block for them to create more robust theories and insights. For example, supply chain management impacts strategy, marketing, finance, accounting, general management, information technology, as well as production, so we can offer important insights from practice in those areas.

In addition, many important theories are grounded in OM topics such as the ResourceBased View (OM holds most of the resources in organizations), performance frontiers, ambidexterity, exploitation versus exploration, project management, and socio-technical systems; as well as constructs like dynamic capabilities (the majority of capabilities are operational), both evolutionary and disruptive innovation (operations and supply chain management are closely related to R\&D and engineering), core competencies, absorptive capacity, and, as noted earlier, supply chain management, as well as others. It is our belief that being relatively new and emerging from the umbrella of others, we now have an opportunity to exploit our knowledge of practice in these topics. But our divisions within the OM field with 
respect to OR/MS versus OM has now brought us to a crossroads. For our field to satisfy both the needs of practice and the expectations of deans looking for top-level academic research, we must reintegrate our approaches to problem solving and knowledge creation.

If we are able to reintegrate OR/MS and OM knowledge creation, we can get back on track toward becoming a core pillar of management, equipped with the tools and rigor to say how theories such as RBV, core competencies, and others, work to give advantages in both manufacturing and services. From that vantage point, we will also be positioned to make substantial contributions in the sphere of innovation, change, and performance given our knowledge about new products and technology. This will permit us to validate or rebut ideas about topics such as absorptive capacity, disruptive innovation, and new business models.

As Abbott (2001) suggested earlier, disciplines become established through a social process. In the case of $\mathrm{OM}$, this social process may involve cooperation with other disciplines to offer new evidence, hypotheses, and theories. We will need to improve at our ability to parlay our field knowledge stemming from our intimate contact with reality and our grappling with the difficult problems facing managers into cross-disciplinary credibility. Our colleagues from other disciplines often demonstrate complete unawareness of this knowledge. And, our ability to transfer this field-based knowledge to students depends crucially on our first establishing its academic credentials.

As noted above, one possible route to showing our colleagues how we can contribute to their research, and hopefully interest them in similar research in our OM journals, is to work with colleagues in our sister disciplines and start contributing to their papers and theories with our empirical, case-based knowledge of real organizations and managers. Another route is to invite researchers from these other disciplines to join us in writing papers for the top journals in our field, perhaps in theirs as well. As a step in this direction, we can start making presentations, or joining them in their presentations, at their conferences such as the Academy of Management, the American Marketing Association, INFORMS, etc. As Amundson (1998, p. 358) says: "The future of theory-driven empirical research in OM is exciting because the field is addressing some of the world's most important and engaging problems." And "...with cooperation and integration with other disciplines and with industry, OM can generate vibrant, exciting, relevant, rigorous research!" This could result in a better appreciation by the other disciplines of what our current transmitter and sink journals offer for their research, where we utilize their theories and they build on our insights about the complexity of those theories in practice. All in all, we feel optimistic that $O M$ has reached an age where we are ready to share our experience on the many things that disciplines like marketing, engineering, $R \& D$, and management theorize about. As we communicate what is learned from this experience, the flow of knowledge from OM to sister disciplines with continue to increase.

\section{Acknowledgments}

We want to acknowledge the help and guidance we received from the multiple editors of JOM and the reviewers who also offered suggestions and positive critical advice in the lengthy development of this paper. 


\section{References}

Abbott, A. (2001). Chaos of Disciplines. Chicago: University of Chicago Press.

ABS (Chartered Association of Business Schools), 2015. Academic Journal Guide. Available at: https://charteredabs.org/academic-journal-guide-2015/, Accessed on: 21 September 2017.

Agarwal, R., Hoetker, G., 2007. A Faustian bargain? The growth of management and its relationship with related disciplines. Academy of Management Journal 50, 1304-1322,

Amundson, S.D., 1998. Relationships between theory-driven empirical research in operations management and other disciplines. Journal of Operations Management 16, 341-359.

Baumgartner, H., Pieters, R., 2003. The structural influence of marketing journals: A citation analysis of the discipline and its subareas over time. Journal of Marketing 67, 123-139.

Behara, R.S., Babbar, S., 2014. Leadership in OM research: a social network analysis of European researchers. International Journal of Operations and Production Management 34(12), 15371563.

Biehl, M., Kim, H., Wade, M., 2006. Relationships among the academic business disciplines: A multimethod citation analysis. Omega 34, 359-371.

Borgatti, S.P., Everett, M.G., and Freeman, L.C., 2002. Ucinet for Windows: Software for Social Network Analysis. Harvard, MA: Analytic Technologies.

Borgatti, S.P., 2002. Netdraw Network Visualization. Harvard, MA: Analytic Technologies.

Browning, T. R., 2016. Design structure matrix extensions and innovations: a survey and new opportunities. IEEE Transactions on Engineering Management 63 (1), 27-52.

Browning, T. R., 2001. Applying the design structure matrix to system decomposition and integration problems: a review and new directions. IEEE Transactions on Engineering Management 48 (3), 292-306.

Cole, J. R., Cole, S., 1973. Social Stratification in Science. Chicago: University of Chicago Press.

Eppinger, S. D., Browning, T. R., 2012. Design Structure Matrix Methods and Applications. Cambridge, MA, USA: MIT Press.

Fox, L.F., Smith, J.S., Cronin, Jr., J.J., Brusco, M., 2013. Weaving webs of innovation. International Journal of Operations and Production Management 33, 5-24.

Franke, R.H., Edlund, T.W., Oster, I.F., 1990. The development of strategic management: journal quality and article impact. Strategic Management Journal 11, 243-253.

Goh, C.-H., Holsaple, C.W., Johnson, L.E., Tanner, J. R., 1997. Evaluating and classifying POM journals. Journal of Operations Management 15, 123-138.

Harzing, A.-W., 2017. Journal Quality List. (60th Edition), Available at: https://harzing.com, Accessed: 21 September 2017.

Holsapple, C.W., Johnson, L.E., Manakyan, H., Tanner, J., 1993. A Citation Analysis of Business Computing Research Journals. Information and Management 25(5), 231-244.

Holsapple, C.W., Johnson, L.E., Manakyan, H., Tanner, J., 1994. A Normalized Citation Analysis. Journal of Management Information Systems 11(1), 131-140.

Kim, Y., Choi, T.Y., Yan, T., Dooley, K., 2011. Structural investigation of supply networks: A social network analysis approach. Journal of Operations Management 29, 194-211.

Ketikovi, M., 2016. On the importance of revisiting what we (thought we) already knew. Journal of Operations Management 41, 62.

Kulkarni, S.S., Apte, U.M., Evangelopoulos, N.E., 2014. The use of latent semantic analysis in operations management research. Decision Sciences 45(5),971-994.

Lee, P-C., Su, H-N., Wu, F-S., 2010. Quantitative mapping of patented technology-the case of electrical conducting polymer nanocomposite. Technological Forecasting \& Social Change 77, 466-478. 
Linderman, K., Chandrasekaran, A., 2010. The scholarly exchange of knowledge in operations management. Journal of Operations Management 28,357-366.

MATLAB, 2012. MATLAB and Statistics Toolbox Release 2012b. Natick, MA: The MathWorks, Inc.

Meredith, J. R., 1973. A Markovian analysis of a geriatric ward. Management Science 19, 604-612.

Meredith, J. R., 1976. Selecting optimal training programs in a hospital for the mentally retarded. Operations Research 24, 899-915.

Meredith, J. R., 2001. Reconsidering the philosophical basis of OR/MS. Operations Research 49, 325-333.

Nerur, S., Rasheed, A.A., Pandey, A., 2016. Citation footprints on the sands of time: an analysis of idea migrations in strategic management. Strategic Management Journal 37, 1065-1084.

Persson, O., Danell, R., Schneider, J., 2009. How to use Bibexcel for various types of bibliometric analysis. In Celebrating Scholarly Communication Studies: A Festschrift for Olle Persson at his 60th Birthday, ed. Åström, F., Danell, R., Larsen, B., and Schneider, J., Leuven, Belgium: International Society for Scientometrics and Informetrics, pp. 9-24.

Petersen, C.G., Aase, G.R., Heiser, D. R., 2011. Journal ranking analyses of operations management research. International Journal of Operations \& Production Management 31, 405-422.

Pilkington, A., 2008. Engineering management or management of technology? A bibliometric study of IEEE-TEM. International Journal of Management Science and Engineering Management 3, 63-70.

Pilkington, A., Fitzgerald, R., 2006. Operations management themes, concepts and relationships: a forward retrospective of the IJOPM. International Journal of Operations and Production Management 11, 1255-1275.

Pilkington, A., Liston-Heyes, C., 1999. Is production and operations management a discipline? A citation/co-citation study. International Journal of Operations and Production Management 19, 7-20.

Pilkington, A., Meredith, J., 2009. The evolution of the intellectual structure of operations management-1980-2006: a citation/co-citation analysis. Journal of Operations Management 27, 185-202.

Pilkington, A., Meredith, J., 2017. The diffusion network of research knowledge in operations management. International Journal of Operations and Production Management (forthcoming).

Price, D. J. D., 1970. Citation measures of hard science, soft science, technology, and nonscience. In Nelson, C. E. and D. K. Pollack, eds. Communication among Scientists and Engineers. Lexington, MA: Heath Press, 3-22.

Ramos-Rodriguez, A R., Ruiz-Navarro, J., 2004. Changes in the intellectual structure of strategic management research: a bibliometric study of the Strategic Management Journal, 1980-2000. Strategic Management Journal 25, 981-1004

Rinia, E. J., Leeuwen, T.N., Bruins, E.E.W., Van Vuren, H.G., Van Raan, A.F. J., 2002. Measuring knowledge transfer between fields of science. Scientometrics 54, 347-362.

Simpson, D., Meredith, J., Boyer, K., Dilts, D., Ellram, L.M., Leong, G.K., 2015. Professional, research, and publishing trends in operations and supply chain management. Journal of Supply Chain Management 51(3), 87-100

Steward, D. V., 1981. The design structure system: a method for managing the design of complex systems. IEEE Transactions on Engineering Management EM-28 (3), 71-74.

Stremersch, S., Verniers, I., Verhoef, P.C., 2007. The quest for citations: Drivers of article impact. Journal of Marketing 71, 171-193.

Stremersch, S., Verhoef, P.C., 2005. Globalization of authorship in the marketing discipline: Does it help or hinder the field? Marketing Science 24(4), 585-594.

Tellis, G.J., Chandy, R.K., Ackerman, D.S., 1999. In search of diversity: The record of major marketing journals. Journal of Marketing Research 36, 120-131. 
Vokurka, R.J., 1996. The relative importance of journals used in operations management research: A citation analysis. Journal of Operations Management 14, 345-355.

Wade, M., Biehl, M., Kim, H., 2006. Information systems is not a reference discipline (and what we can do about it). Journal of the Association for Information Systems 7, 247-269.

Zinkhan, G.M., Roth, M.S., Saxon, M.J., 1992. Knowledge development and scientific status in consumer behavior research: a social exchange perspective. Journal of Consumer Research 19, 282-291. 
Table 1 Distribution of citations among OM's top-30 journals: 1980-2009

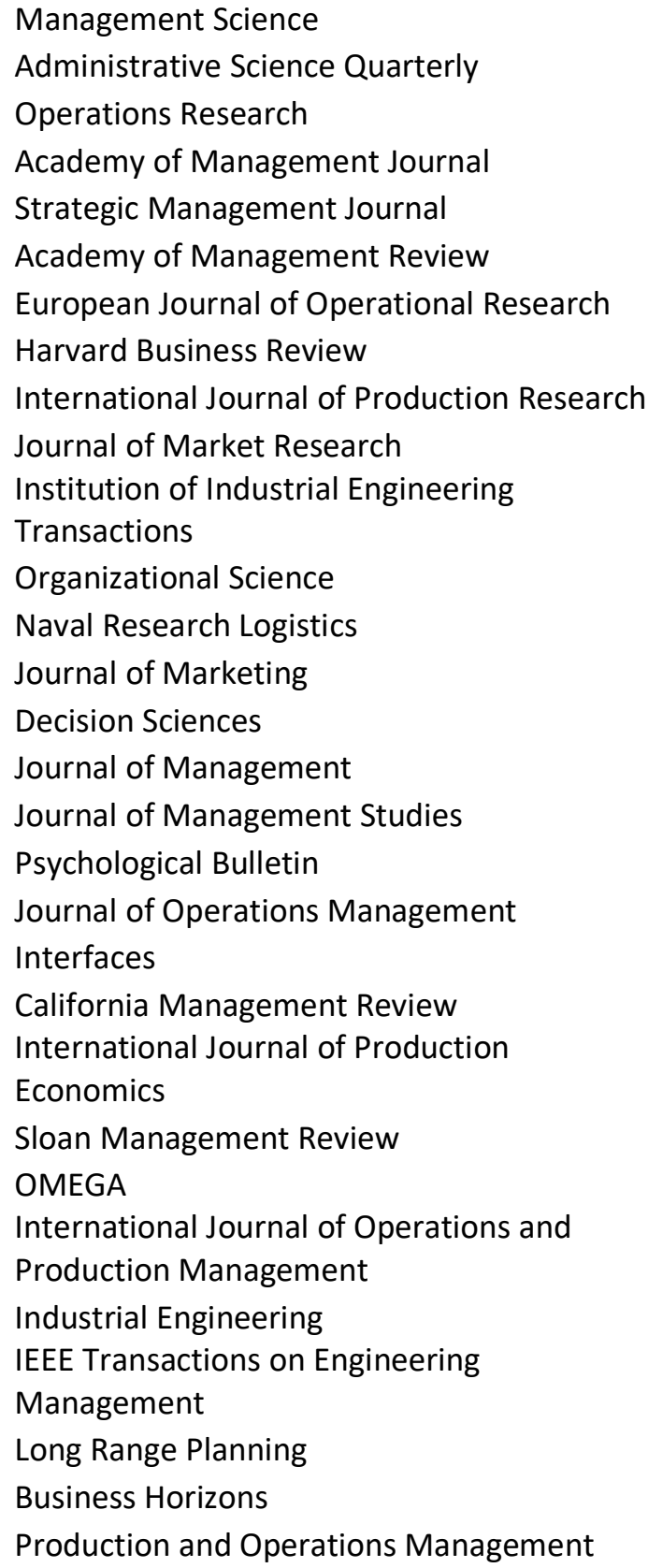

\begin{tabular}{|c|c|c|}
\hline $\begin{array}{l}\text { Journal } \\
\text { MS }\end{array}$ & $\begin{array}{c}\% \text { Citations } \\
15.2 \%\end{array}$ & $\begin{array}{c}\text { Source/Trans/Sink } \\
\text { Source }\end{array}$ \\
\hline ASQ & $9.0 \%$ & Source \\
\hline OR & $8.4 \%$ & Source \\
\hline AMJ & $7.4 \%$ & Source \\
\hline SMJ & $6.8 \%$ & Source \\
\hline AMR & $6.5 \%$ & Source \\
\hline EJOR & $4.9 \%$ & Trans \\
\hline HBR & $4.1 \%$ & Source \\
\hline IJPR & $3.4 \%$ & Trans \\
\hline JMR & $3.4 \%$ & Trans \\
\hline IIET & $3.1 \%$ & Trans \\
\hline OS & $2.7 \%$ & Trans \\
\hline NRL & $2.5 \%$ & Sink \\
\hline JMar & $2.4 \%$ & Trans \\
\hline DS & $2.2 \%$ & Trans \\
\hline JMan & $2.1 \%$ & Trans \\
\hline JMS & $2.0 \%$ & Sink \\
\hline PB & $1.9 \%$ & Trans \\
\hline JOM & $1.7 \%$ & Trans \\
\hline Intf & $1.5 \%$ & Sink \\
\hline CMR & $1.4 \%$ & Trans \\
\hline IJPE & $1.4 \%$ & Sink \\
\hline SMR & $1.4 \%$ & Trans \\
\hline OMEGA & $1.2 \%$ & Sink \\
\hline IJOPM & $1.0 \%$ & Sink \\
\hline IE & $0.6 \%$ & Sink \\
\hline IEEETEM & $0.6 \%$ & Sink \\
\hline LRP & $0.6 \%$ & Sink \\
\hline $\mathrm{BH}$ & $0.4 \%$ & Sink \\
\hline POM & $0.3 \%$ & Sink \\
\hline
\end{tabular}


Table 2 Group knowledge flows with Operations Management Group

\begin{tabular}{lrrrr} 
Group & \multicolumn{4}{c}{ \% Citations of Three OM Journals/By Each Group } \\
& \multicolumn{1}{c}{ Overall } & \multicolumn{1}{c}{$80 \mathrm{~s}$} & \multicolumn{1}{c}{$90 \mathrm{~s}$} & \multicolumn{1}{c}{ 00s } \\
OR/MS & $2.39 / 37.33$ & $0.51 / 60.62$ & $1.51 / 45.70$ & $3.25 / 33.30$ \\
OM & $1.45 / 12.24$ & $0.12 / 1.94$ & $0.75 / 8.52$ & $2.10 / 14.03$ \\
Engineering & $0.21 / 4.06$ & $0.09 / 10.95$ & $0.11 / 6.24$ & $0.29 / 2.95$ \\
Management & $0.07 / 21.93$ & $0.09 / 9.33$ & $0.07 / 14.28$ & $0.07 / 25.09$ \\
Practice & $0.02 / 18.55$ & $0.01 / 16.06$ & $0.02 / 21.99$ & $0.02 / 17.61$ \\
Marketing & $\underline{0.01 / 5.90}$ & $\underline{0.00 / 1.10}$ & $\underline{0.00 / 3.27}$ & $\underline{0.01 / 7.02}$ \\
Total citations & $4.15 / 100.00$ & $0.82 / 100.00$ & $2.46 / 100.00$ & $5.74 / 100.00$
\end{tabular}


Fig. 1. Knowledge flows between journals over the 30-year period: Design Structure Matrix

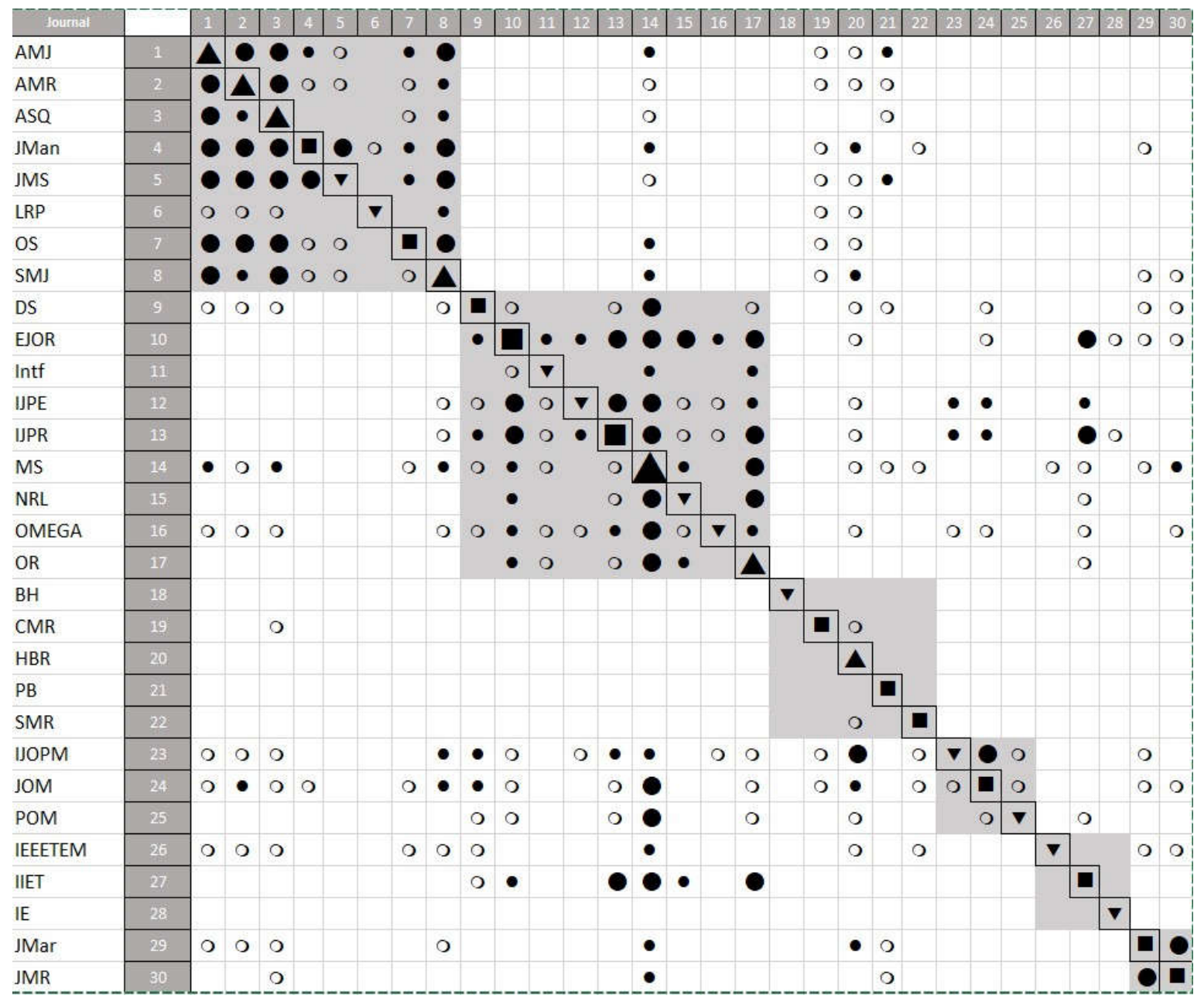

Key: Read across a row to see outflows of citations and down a column to see inflows. Diagonals show source $(\mathbf{\Delta})$, transmitter $(\square)$ or sink $(\boldsymbol{\nabla})$, symbol size represents net inflow; Circles show the flow of citations: greater than 1501, • between 701 and 1500, o between 245 and 700; for clarity less than 244 citations are not shown. 
Fig. 2. Networks of groups by decade

Fig. 2a. Network of Groups, 1980s

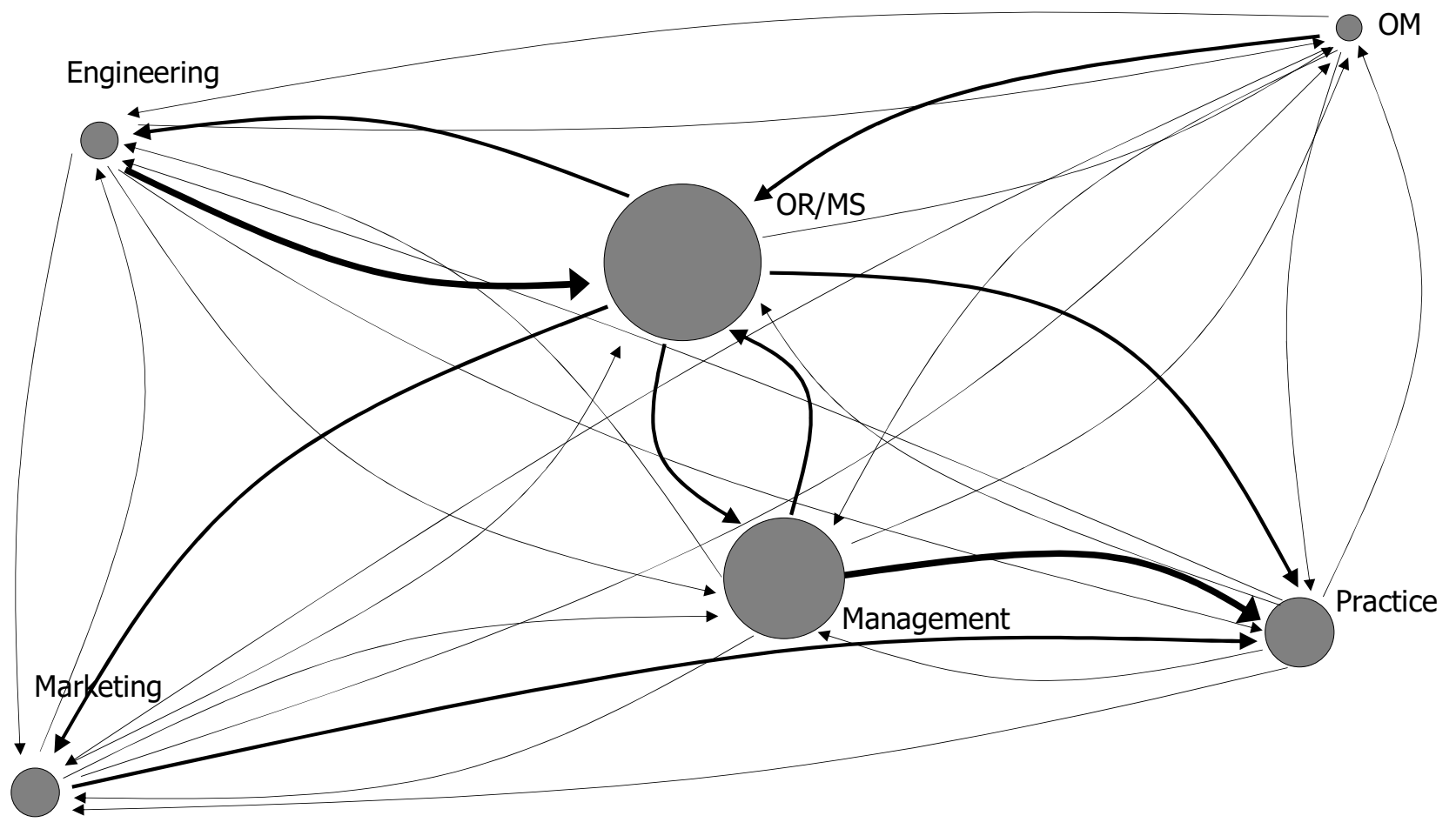


Fig. 2b. Network of Groups, 1990s

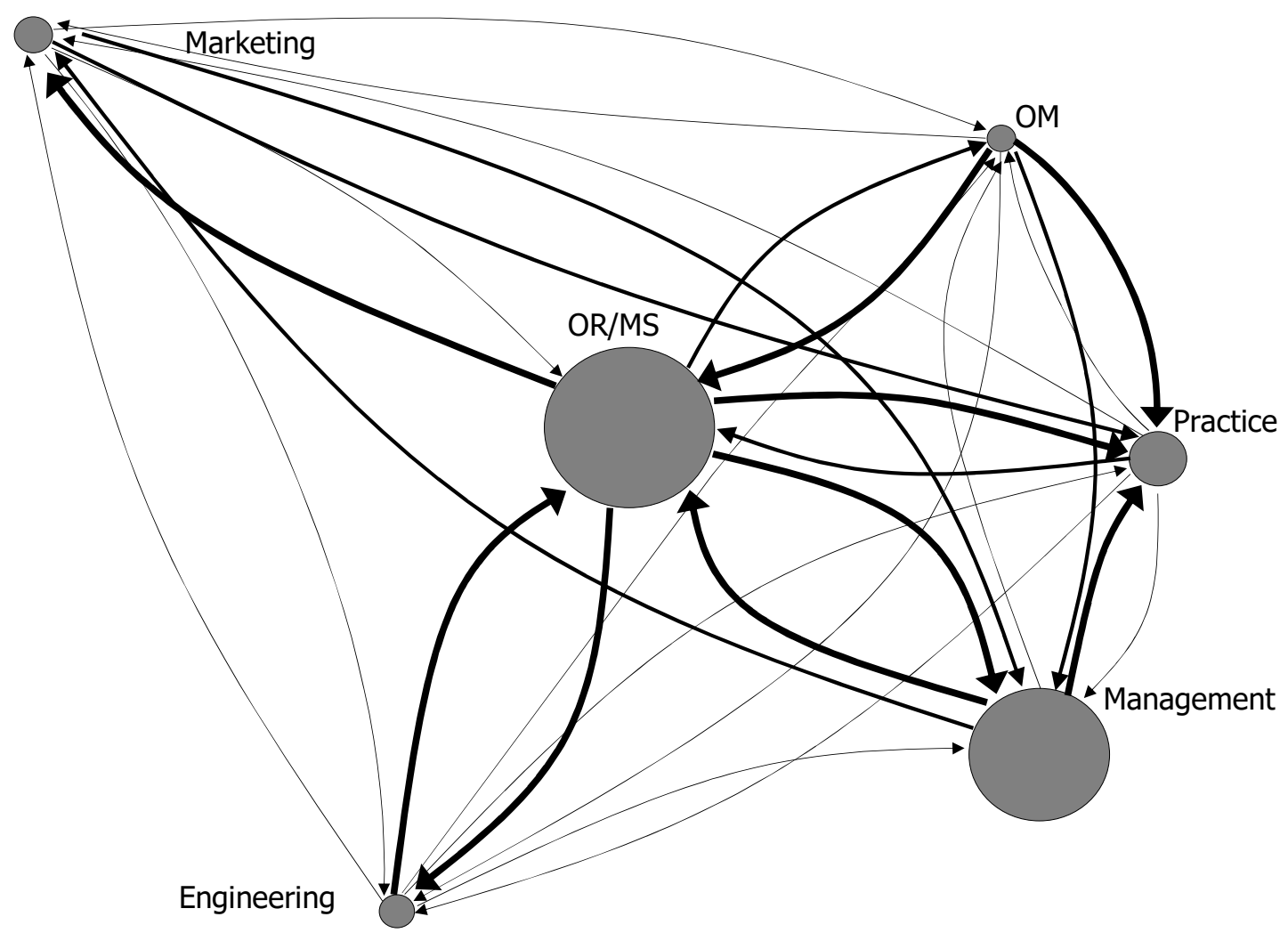


Fig. 2c. Network of Groups, 2000s

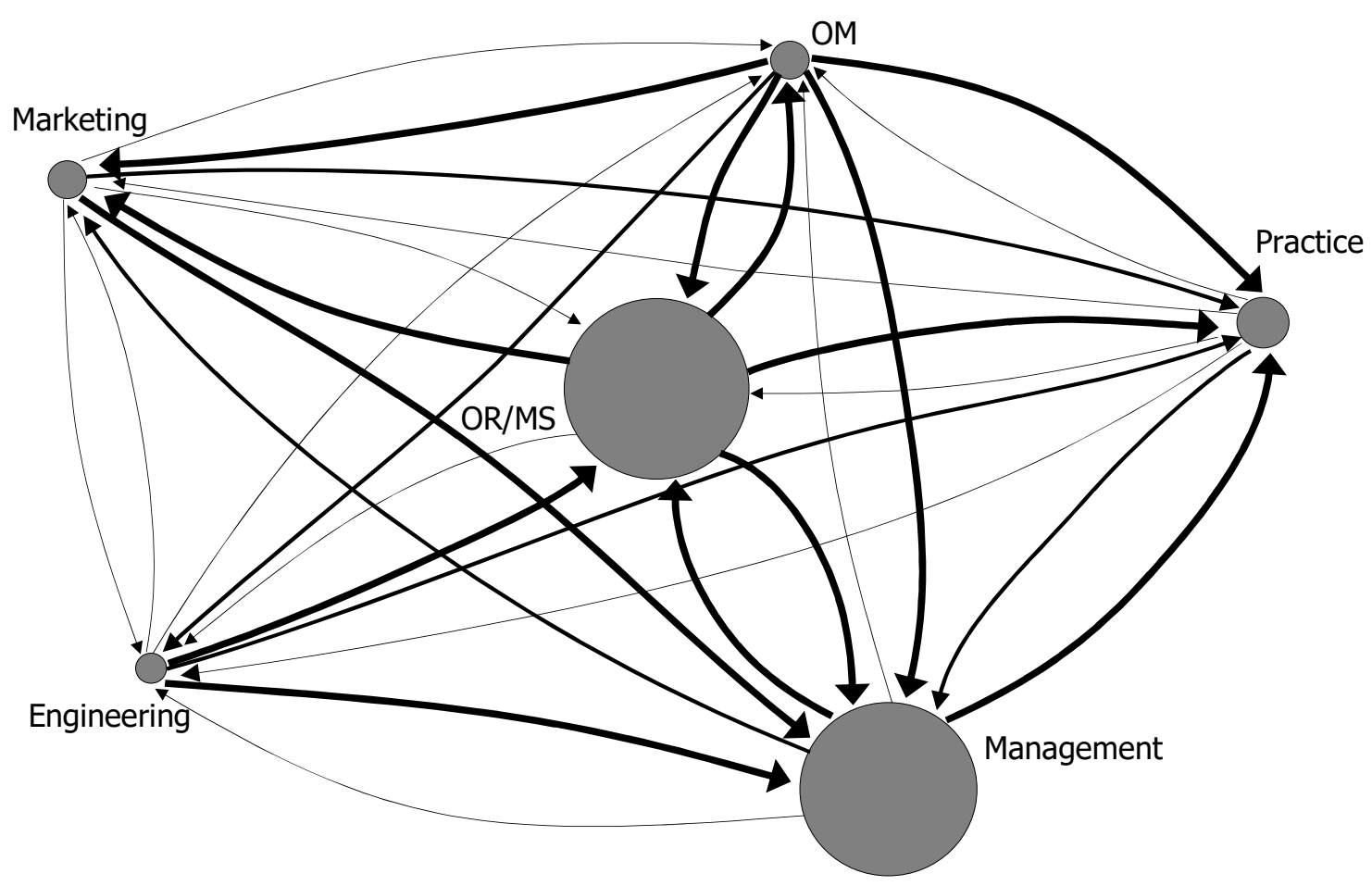

